\title{
A trajetória de obras de Vigotski: um longo percurso até os originais'
}

\author{
The trajectory of Vygotsky's works: \\ a long way to the originals
}

\author{
Zoia PRESTES ${ }^{2}$ \\ Elizabeth TUNES 2,3
}

\begin{abstract}
Resumo
Muitas obras de Vigotski sofreram adulterações mundo afora, inclusive na Rússia. Neste artigo, é analisada a trajetória de três de seus livros e suas traduções, na União Soviética, na Rússia e no Brasil. Buscou-se identificar adulterações que pudessem conduzir a equívocos na interpretação das ideias do autor, ou que pudessem dificultar a compreensão da trajetória de seu pensamento. Para tanto, foi realizado um cotejamento de diferentes edições russas e de versões em outros idiomas. Foram identificadas edições com cortes de trechos importantes, com acréscimos de capítulos inexistentes no livro original, e com traduções equivocadas do russo para o português.
\end{abstract}

Unitermos: Histótia da Psicologia. Vigotski. Tradução.

\begin{abstract}
Many of Vygotsky's works have been adulterated all around the world, including in Russia. In this article the trajectory of three books by the author including translations, in the Soviet Union, Russia and Brazil was analyzed in order to identify alterations that may lead to misinterpretation of Vygotsky's ideas and could make it difficult to understand the historical trajectory of his thought. Therefore, a comparison was made of different Russian editions and translations into other languages. Editions were found in which important sections had been eliminated, addition of chapters that did not exist in the original version and mistranslations of terms from Russian to Portuguese.
\end{abstract}

Uniterms: History Psychology. Vygotsky. Translating.

Este artigo analisa a trajetória de alguns trabalhos de Vigotski na União Soviética, na Rússia e no Brasil, incluindo suas traduções. Muitas obras de Vigotski sofreram e ainda sofrem adulterações e mutilações mundo afora, inclusive na Rússia. Por exemplo, em algumas traduções para o português a expressão atividade de brincar foi traduzida como brinquedo; obutchenie como aprendizagem; retch como linguagem; tvortchestvo como arte. Todos esses conceitos são de suma importância no corpo de sua teoria, mas sofreram com a falta

$\boldsymbol{\nabla} \mathbf{\nabla} \boldsymbol{\nabla}$

- Artigo elaborado a partir da tese de Z. PRESTES, intitulada "Quando não é quase a mesma coisa: análise de traduções de Lev Semionovitch Vigotski no Brasil". Universidade de Brasilia, 2010.

2 Universidade Federal Fluminense, Faculdade de Educação. Campus Gragoatá, Bloco D, Niterói, RJ, Brasil. Correspondência para/Correspondence to: Z. PRESTES. E-mail: <zoiaprestes@yahoo.com.br>.

3 Universidade de Brasília, Faculdade de Educação. Brasília, DF, Brasil. 
de cuidado nas traduções, acarretando distorções na interpretação das ideias de Vigotski.

Para realizar a análise de algumas obras e de suas traduções, foi realizado um cotejamento de diferentes originais russos e de versões em outros idiomas. Foram selecionados alguns trabalhos que tratam de determinados conceitos da teoria histórico-cultural que estão muito presentes no vocabulário educacional brasileiro, mas que, devido a traduções pouco cuidadosas ou a intenções de apresentar um Vigotski menos marxista e menos comprometido com o regime socialista, acarretaram distorções e interpretações equivocadas do seu pensamento.

Quando se analisa a extensa produção escrita de Vigotski, nota-se que foram poucos os livros que escreveu com a intenção de serem livros. Pode-se afirmar que livros mesmo foram os seguintes: Psirrologuia iskusstva (Psicologia da Arte), escrito em 1925 e publicado somente em 1965; Pedagoguitcheskaia psirrologuia (Psicologia Pedagógica) de 1926, e Michlenie e retch (traduzido no Brasil como Pensamento e linguagem ou Construção do pensamento e da linguagem), de 1934; e uma série de livros didáticos para o ensino à distância (por correspondência), tais como Pedologia da idade escolar (Pedologuia chkolnogo vozrasta), de 1928, Pedologia da juventude (Pedologuia iunochevskogo vozrasta), de 1929, e Pedologia do adolescente (Pedologuia podrostka), escrito entre 1930 e 1931. Alguns capítulos deste último livro didático foram republicados no volume 4 de Obras reunidas (Sobranie sotchineni).

Os livros publicados principalmente após sua morte reúnem artigos, textos e estenografias de aulas proferidas ou discursos em eventos científicos. O levantamento mais completo e sistematizado está apresentado em anexo à biografia escrita por Vigodskaia e Lifanova (1996) e relaciona 274 títulos. Estão indicados nessa lista até mesmo alguns artigos e textos que ainda permanecem em forma de manuscritos, como, por exemplo, A teoria da base e da superestrutura (Teoria bazissa inadstroiki), de 1925; Resenha do livro de Otto Rühle: o psiquismo da criança proletária (Rets Na kn.: Otto Rühle. Psirrica proletarskogo rebionka), de 1926; Aulas sobre a psicologia do desenvolvimento (Lektsii po psirrologuii razvitia), de 1928, para apenas citar alguns (Zaverchneva,

328 2007).
Um contemporâneo e colaborador de Vigotski, Daniil Borissovitch Elkonin, indica, por sua vez, que ele escreveu cerca de 180 trabalhos (Elkonin, 1984). É importante ressaltar a tentativa de relacionar a produção escrita de Vigotski. Mas, apesar disso, sabe-se, por relatos de sua filha Guita, que muitos textos ainda permanecem em forma de manuscrito. Isso explica, em parte, por que textos de Vigotski foram publicados ao gosto de cada organizador. Além de ficarem proibidas na União Soviética (URSS), ao longo de quase 20 anos, suas obras nem sempre tiveram um destino digno. A seguir, será examinado, detalhadamente, o percurso de algumas de suas publicações. Busca-se traçar o longo percurso de obras publicadas até os seus originais, mostrando adulterações, cortes e censuras que sofreram ao longo da história.

\section{Psicologia da arte (psirrologuia iskusstva)}

Na bibliografia dos trabalhos de Vigotski, apresentada por sua filha, o livro Psicologia da arte aparece na ordem cronológica de escrita, ou seja, no ano de 1925. No entanto, a primeira edição do livro, que ficou a cargo da editora soviética Iskusstvo, foi lançada apenas em 1965, com 379 páginas, tendo como seu editor Viatcheslav Vsievolodovitch Ivanov. A edição era acompanhada de um prefácio de A.N. Leontiev e de comentários que, segundo a filha de Vigotski, representam parte de investigações científicas do próprio Ivanov. Em 1968, a mesma editora Iskusstvo publicou uma segunda edição corrigida e ampliada, com 576 páginas, trazendo anexo o trabalho de Vigotski sobre Hamlet (Vigodskaia \& Lifanova, 1996). A terceira edição pela mesma editora saiu em 1986, com 572 páginas. A editora Pedagoguika, como complemento à edição das Obras reunidas de Vigotski, lançou uma edição em 1987, com 344 páginas e um posfácio de M.G. larochevski.

Existem algumas versões sobre as razões para o livro não ter sido publicado ainda nos anos 1920. A.N. Leontiev, no prefácio à primeira edição, diz que havia motivos internos e por isso Vigotski nunca mais, em sua trajetória, retornou ao tema da arte (Leontiev, 1986). Já Vigodskaia e Lifanova (1996) citam a versão de que Vigotski ficou insatisfeito com o método de análise utilizado e sentia necessidade de novos pontos de partida. 
Essa circunstância deve ser levada em consideração por quem procura em Psicologia da arte respostas para as questões atuais da psicologia contemporânea da criação e da estética. As respostas não satisfaziam o próprio Vigotski e, provavelmente, não podem satisfazer o pesquisador de hoje (Vigodskaia \& Lifanova, 1996, p.94).

Porém, Guita não concorda com nenhuma das versões e, com base em documentos dos arquivos de família, atesta a inverossimilhança de ambas. Em 9 de novembro de 1925, foi assinado entre a editora Leningradskoie Gossudarstvennoie Izdatelstvo e Vigotski um contrato para a publicação do livro Psicologia da arte. Num post scriptum da carta endereçada a L.S. Sarrarov em 1926, Vigotski comenta: "Com a Psicologia da arte tudo se ajeitou. Não sei se para melhor, mas parece que será publicada" (Vigodskaia \& Lifanova, 1996, p.94). Guita também menciona a ata da reunião do conselho editorial do Instituto Estatal de Psicologia Experimental, que registra a discussão sobre a autorização da publicação da dissertação de Vigotski. A decisão é favorável à publicação, mas todas as despesas e responsabilidades relacionadas com a impressão do livro deveriam ficar a cargo do autor (Vigodskaia \& Lifanova, 1996).

Atualmente, há várias edições do livro, também disponíveis em versões digitais em diferentes sítios eletrônicos russos. A diferença das edições quanto ao número de páginas pode ser atribuída aos anexos que foram posteriormente acrescentados: o conto Liorrkoie dirranie (Leve alento), de Bunin, e a monografia de Vigotski, Traguedia o Gamlete, printse Datskom (A tragédia de Hamlet, príncipe da Dinamarca).

Em um dos comentários à edição do livro de 1986, encontra-se a informação de que o texto Traguedia o Gamlete, printse Datskom (A tragédia de Hamlet, príncipe da Dinamarca) conservou-se nos arquivos em duas versões. A primeira, em forma de rascunho, com as datas de 5 de agosto a 12 de setembro de 1915, indicando a cidade de Gomel como local de realização e sem o número de páginas. A segunda versão, passada a limpo, tem a data de 14 de fevereiro a 28 de março de 1916 e indica que foi escrita em Moscou e é composta de 12 cadernos. Ao que parece, a de 1916 é a versão final que serviu de base para o capítulo que tem o mesmo título no livro Psicologia da arte - Traguedia o Gamlete, printse Datskom (Tragédia de Hamlet, príncipe da Dinamarca).
Essa hipótese pode ser levantada ao analisar o Projeto de publicação das Obras Completas que está sendo desenvolvido pela família do pensador. O Projeto prevê publicar no primeiro volume, intitulado Dramaturgia e teatro, resenhas teatrais, Hamlet com observações não publicadas, com apontamentos sobre Hamlet retirados dos cadernos de anotações (Zaverchneva, 2007). No segundo volume, intitulado Literatura e arte, deverão constar resenhas de livros e trabalhos filológicos: Anotações às margens de livros e passadas a limpo em cadernetas do leitor Vigotski - não publicadas; a Tragicomédia das buscas, Socialismo e sionismo, Psicologia da arte completa com duas cartas de K. K. Kornilov sobre Psicologia da arte (Zaverchneva, 2007). Pode-se observar que a monografia de Vigotski sobre Hamlet é tratada como um trabalho separado do livro Psicologia da arte.

Sabe-se que a primeira edição de Psicologia da arte teve por base a versão final escrita à máquina pelo autor, mas sofreu alguns cortes por parte dos editores que retiraram citações que consideraram desnecessárias. Para a segunda edição, o texto foi conferido com o exemplar encontrado por N.I. Kleiman na biblioteca do amigo de Vigotski, o cineasta Serguei Mirrailovitch Eisenstein. Nela, foram preservados todos os comentários de Vigotski, e o texto da monografia sobre Hamlet foi conferido com os manuscritos do autor (Vigotski, 1986, p.110, comentário 46).

A primeira edição do livro, de 1965, como já foi dito, traz o prefácio de A. N. Leontiev, que faz uma breve referência à trajetória de Vigotski na psicologia e detém-se nas questões abordadas no livro. Leontiev (1986) diz que é nesse livro que Vigotski sintetiza seus trabalhos do período entre 1915-1922, pois, além de lecionar em escolas de Gomel, escreveu muitas resenhas e trabalhos de crítica literária. Na bibliografia anexa à sua biografia, estão relacionados 87 trabalhos de crítica literária. Muitos foram publicados em revistas da época e nunca foram reeditados; outros permanecem em forma de manuscrito nos arquivos da família. Leontiev afirma que, nesse trabalho, Vigotski utiliza-se do método de análise para refletir sobre o que faz da obra artística uma obra de arte.

É importante destacar que o próprio Vigotski, no prefácio do livro, diz que resume uma série de trabalhos pequenos e grandes, na área da arte e da psico- 
logia (Vigotski, 1998). Segundo larochevski (2007), ainda em Gomel, atuando como professor, Vigotski refletia sobre a influência da literatura em seus educandos e sobre a percepção da literatura pela alma infantil. larochevski chama a atenção para a enorme diferença que existe entre a monografia sobre Hamlet do jovem Vigotski e o capítulo do livro que leva o mesmo título. Ele critica a abordagem de Ivanov (1986, p.193), que diz que as duas versões estão unidas pela investigação da tragédia sem pontos de vista preconcebidos: "... é exatamente esse aspecto do trabalho (na primeira versão) que foi desenvolvido coerentemente no capítulo VIII do Psicologia da arte".

Para larochevski (2007), o equívoco de Ivanov está na aproximação das duas versões, enquanto, para ele, basta ler as duas para perceber que há uma diferença fundamental do ponto de vista filosófico e psicológico. larochevski chega a contrariar o próprio autor de Psicologia da arte, dizendo que Vigotski revê radicalmente seus dois textos. Além disso, larochevski afirma que, nas referências de Psicologia da arte, Vigotski relaciona os artigos e as notas que fez entre 1916-1917, ou seja, período em que seguia os padrões da crítica impressionista que via a arte como "floração do espírito" (p.160) e tinha a convicção de que a verdadeira obra artística realiza a percepção direta pelo leitor. larochevski argumenta que, enquanto trabalhava em Psicologia da arte, Vigotski tinha como professor Plerranov, e não Airrenvald; por isso, seus escritos anteriores a 1917 não podiam fundamentar um trabalho escrito do ponto de vista da estética e da psicologia materialista.

O que é possível afirmar é que muitas ideias desenvolvidas por Vigotski em Psicologia da arte, de 1925, estão também presentes em seu importante estudo Imaginação e criação na infância, escrito um pouco mais tarde, em 1930. Por exemplo, no capítulo 2, que trata da imaginação e da realidade, Vigotski destaca quatro formas de relação entre essas instâncias. A primeira forma consiste no fato de que toda obra da imaginação constrói-se sempre de elementos tomados da realidade e presentes na experiência anterior da pessoa. Já a segunda forma dessa relação é mais complexa e diz respeito à articulação entre o produto final da imaginação e um fenômeno complexo da realidade:

Quando lemos o jornal e nos informamos sobre 330 diretamente, quando uma criança estuda geografia ou história, quando, por meio de uma carta, tomamos conhecimento do que está acontecendo a uma outra pessoa, em todos esses casos a nossa imaginação serve à nossa experiência (Vigotski, 2009, p.25).

A terceira forma de relação entre a atividade de imaginação e a realidade, prossegue Vigotski, é de caráter emocional e se manifesta de dois modos: por um lado, qualquer sentimento, qualquer emoção tende a se encarnar em imagens conhecidas correspondentes a esse sentimento; por outro, a imaginação influi no sentimento. A quarta e última forma é que a construção da fantasia pode ser algo completamente novo, que nunca aconteceu na experiência de uma pessoa nem tem nenhuma correspondência com qualquer objeto existente; no entanto, ao ser externamente encarnada, ao adquirir uma concretude material, essa imaginação "cristalizada", que se fez objeto, começa a existir realmente no mundo e a influir sobre outras coisas (Vigotski, 2009, p.29).

Pode-se então sintetizar as quatro formas de relação existentes, para Vigotski, entre a fantasia e a realidade como as seguintes: a imagem criada com base na realidade; a imagem criada com base na experiência de outras pessoas; o sentimento encarnado na imagem que, por sua vez, influi no sentimento; e, por último, a criação de algo totalmente novo que jamais existiu na experiência humana e que se torna realidade. $O$ ponto de confluência entre essas ideias e as que estão em Psicologia da arte ocorre quando Vigotski pergunta para que é necessária uma obra artística. "Será que ela realmente influencia o nosso mundo interior, nossas ideias e sentimentos da mesma forma que o fazem os instrumentos técnicos sobre o mundo externo, o mundo da natureza?" (Vigotski, 2009, p.31). Para Vigotski, as obras de arte têm uma lógica interna das imagens em desenvolvimento, uma lógica que está condicionada à relação que a obra estabelece entre seu próprio mundo e o mundo externo, lógica essa que é impossível de ser controlada pelo autor. É possível dizer que essa ideia está intimamente ligada ao que ele denomina de reação estética, em Psicologia da arte. Ele diz que nenhum elemento na obra de arte é importante por si só. O importante é a reação emocional que ela provoca, ou seja, a base da reação estética são os afetos provocados pela arte, os sentimentos vivenciados por nós em toda sua 
realidade e força e que encontram sua descarga na atividade da fantasia (Vigotski, 1998).

Psicologia da arte já foi traduzido e editado na Hungria (Muveszetpszichologia. Budapest: Kossuth Kiado, 1968), no Japão (Geijutsu shiurigaku. Tokyo: Meiji tosho schuppan, 1971), na Inglaterra em edição conjunta com o Massachusetts Institute of Technology dos Estados Unidos (Psychology of art. Cambridge - Mass.: M.I.T. Press, 1971), na Espanha (Psicologia del arte. Barcelona, Barral, 1972), na Itália (Psicologia dell'arte. Roma: Editori Rraniti, 1972), na Romênia (Psihologia artei. Bucuresti: Univers, 1973), na Alemanha (Psychologic der Kunst. Dresden: Verlag der Kunst, 1976), e na Tchecoslováquia (Psychologic umeni. Praha: Literarnevedna rada, 1981). No Brasil, o livro Psicologia da arte foi editado pela primeira vez pela editora Martins Fontes, com tradução de Paulo Bezerra, em 2001.

Esse importante trabalho de Vigotski tem por objetivo fundamental estabelecer as bases teóricas da psicologia da arte, bem como compreender a arte como atividade humana, as relações da obra com o expectador e da obra com a própria obra. Para Leontiev (1986, p.3), por exemplo, a análise da estrutura da obra artística é a principal abordagem do livro;

Normalmente, a análise da estrutura relaciona-se em nossa consciência com a noção da análise puramente formal, desviada do conteúdo da obra. No entanto, em Vigotski, a análise da estrutura não está fora do conteúdo, mas o penetra, pois, o conteúdo da obra artística não é o material, não é a fábula; seu conteúdo efetivo é seu conteúdo ativo, aquilo que determina o caráter específico da vivência (perejivanie) estética provocada por ele. Esse conteúdo não é simplesmente introduzido de fora, mas é criado na obra pelo artista. O processo de criação desse conteúdo é que se cristaliza, sedimenta-se na estrutura da obra, assim como podemos dizer que a função fisiológica sedimenta-se na anatomia do órgão.

Também para larochevski, Vigotski via na arte uma chave especial da alma humana, da compreensão do sentido da vida humana (larochevski, 2007).

O objeto de estudo de Vigotski é composto de diferentes obras literárias. Primeiramente, ele apresenta a crítica às teorias predominantes, que entendiam a arte como conhecimento e como procedimento. Uma crítica contundente é feita à análise da arte do ponto de vista psicanalítico. Em seguida, o autor se debruça sobre a análise de diferentes obras literárias e escolhe a fábula, a novela, o conto e a poesia. Como diz Leontiev (1986), a análise dessas obras é muito mais difícil porque seu material é a língua, o material semântico, relevante para o conteúdo que está encarnado nele. Por último, o autor apresenta suas reflexões sobre a catarse, a psicologia da arte e sobre a arte e a vida.

Sem dúvida, esse livro de Vigotski configura-se como leitura obrigatória para todos que estudam não só seu pensamento, mas para todos aqueles que estão interessados nos estudos teóricos sobre a arte. É evidente que as buscas de Vigotski (1998) envolviam a compreensão da função da arte na sociedade e na vida da humanidade. Numa só frase, ele resume de maneira brilhante que:"A arte é o social em nós"(p.281), pois para ele a arte tem a função de superação do sentimento individual, e seu aspecto criativo está no fato de ela possibilitar a transferência de uma vivência comum.

O termo vivência (em russo perejivanie) tem enorme significado para Vigotski. Ao longo dos estudos desse trabalho de Vigotski, foi realizada uma comparação do original russo com a tradução brasileira (Vigotski, 2001a). Por ser perejivanie um conceito muito importante, qualquer tradução deve levar em conta o significado atribuído a essa palavra. Nesse sentido, é inconcebível que a mesma tradução apresente o termo perejivanie ora como emoção, ora como vivência, ora como sentimento, como ocorre na tradução feita por Paulo Bezerra.

Para exemplificar, o Quadro 1 transcreve um pequeno trecho em que a palavra perejivanie é traduzida como emoção.

O conceito perejivanie é discutido por Leontiev (2003) no texto Estudo sobre o meio nos trabalhos pedológicos de L.S. Vigotski (Utchenieo sredevpedologuitcheskirh rabotarh L.S. Vigotskogo). Segundo seu filho e seu neto, esse seria o único trabalho em que Alesksei Nikolaievitch Leontiev apresenta uma crítica a Vigotski. Pelo que se sabe, foi publicado pela primeira vez no volume no 1 da conceituada revista do Instituto de Psicologia da Universidade de Moscou, Questões da psicologia (Voprosi psirrologuii), de 1998. No texto, Leontiev (2007) cita o trabalho de Vigotski Fundamentos da pedologia (Osnovi 
pedologuii ${ }^{4}$ ) e transcreve um trecho em que é definido o conceito:

Perejivanie de alguma situação ou de algum ambiente define qual será a influência dessa situação ou desse ambiente sobre a criança. Dessa forma, não é aquele ou outro momento, tomado independentemente da criança, mas é esse momento, radicalmente transformado pela perejivanie da criança, e que pode definir como esse momento irá influenciar a marcha do futuro desenvolvimento (p.251).

Com base nesse trecho, A.N. Leontiev diz que perejivanie, para Vigotski, é, consequentemente, aquilo em que se transforma radicalmente para a criança o ambiente que a cerca. Segundo Leontiev (2007), é fácil compreender que qualquer objeto apresenta-se de modo diferente para uma criança de um ano ou para outra de sete anos, mas isso é apenas uma descrição dos fatos, pois a questão crucial consiste em desvendar de que forma e o que realmente define uma ou outra perejivanie da criança numa dada situação. Então, conclui Leontiev (2007), a apresentação do conceito em si não resolve o problema, mas o faz retornar de novo com uma única diferença: o lugar que, antes, pertencia por completo à personalidade da criança, agora, está ocupado pela perejivanie como uma forma concreta de revelação dessa personalidade completa.

No entanto, pode-se dizer que já temos a resposta, pois a forma como o ambiente influencia a criança e a forma como influencia as especificidades da criança, por sua vez, é definida pela perejivanie. Porém, é uma solução fictícia do problema já que se encerra em um círculo lógico vicioso e nele podemos circular infinitamente, pois perejivanie não apresenta movimento próprio e, conseqüentemente, os dois aspectos surgem em relação a ela (perejivanie) como forças externas (Leontiev, 2007, p.252).

Em busca de outra explicação, A.N. Leontiev recorre novamente ao texto do próprio Vigotski, na mesma obra em que diz que a situação influencia a criança de maneiras diferentes, dependendo do quanto ela compreende seu sentido e significado. A essa compreensão do significado, Vigotski denomina-a osoznanie, que é o quanto a criança tem consciência da situação vivenciada 5 . No entanto, A.N. Leontiev diz que o conceito

Quadro 1. Traduções de um trecho do original russo.

\begin{tabular}{|c|c|c|}
\hline Original russo & Tradução de Paulo Bezerra & Sugestão de tradução das autoras deste artigo \\
\hline $\begin{array}{l}\text { Таким образом, механизм } \\
\text { психологических процессов } \\
\text { соответсвующих произведению } \\
\text { искусства, намечается из этой } \\
\text { аналогии, причём устанавливается, } \\
\text { что символичность или образность } \\
\text { слова равняется его поэтичности, } \\
\text { то есть основой художественного } \\
\text { пере жив ания станов и тся } \\
\text { образность, а об иим его } \\
\text { характером - обычные свойства } \\
\text { и н т е л е к ту а ль но г о и } \\
\text { познавате льного прочесса } \\
\text { (Выготский, 1998, стр. } 30)\end{array}$ & $\begin{array}{l}\text { Dessa analogia, esboça-se o mecanismo } \\
\text { dos processos psicológicos corresponden- } \\
\text { tes à obra de arte, e ainda se estabelece que } \\
\text { o caráter de símbolo ou imagem da palavra } \\
\text { equipara-se à sua poeticidade e, deste mo- } \\
\text { do, o fundamento da emoção artística } \\
\text { passa a sero caráter de imagem cuja nature- } \\
\text { za geral é constituída pelas propriedades } \\
\text { comuns do processo intelectual e cogni- } \\
\text { tivo (Vigotski, 2001a, p.34) }\end{array}$ & $\begin{array}{l}\text { Assim sendo, dessa analogia esboça-se o meca- } \\
\text { nismo dos processos psicológicos correspon- } \\
\text { dentes à obra de arte; além disso, estabelece-se } \\
\text { que a simbologia ou a imagem da palavra } \\
\text { igualam-se a sua poeticidade. Ou seja, a imagem } \\
\text { torna-se a base da vivência artística e seu caráter } \\
\text { geral são as propriedades comuns dos processos } \\
\text { intelectual e de conhecimento }\end{array}$ \\
\hline
\end{tabular}

$\boldsymbol{\nabla} \boldsymbol{\nabla} \boldsymbol{\nabla}$

- Segundo a referência constante do livro de A.N. Leontiev Stanovlenie psirrologuii deiatelnosti (A constituição da psicologia da atividade (2003), organizado por seu filho e seu neto, esse trabalho de Vigotski foi publicado em 1934, pela editora da Universidade de Moscou, com 89 páginas. No entanto, no projeto de publicação das Obras Completas, há uma observação que diz que ele nunca fora publicado e que consiste de aulas proferidas em 1934 , contendo 211 páginas.

5 Os organizadores do The Collected Works of L.S. Vygotsky ressaltam em nota a importante diferença que existe entre as duas palavras russas soznanie e osoznanie e dizem que traduzir ambos os termos como consciência é introduzir uma confusão que não existe no texto original russo. Soznanie significaconsciência, mas osoznanie é o despertar da consciência reflexiva, ou discernimento e controle consciente do ato de pensar (Tunes, 2000). 
perejivanie não está plenamente desvendado em Vigotski e levanta a questão sobre a importância de aprofundar a relação entre a consciência da criança e sua atividade no ambiente circundante e em sua realidade objetiva (Leontiev, 2007).

Ainda que o trabalho de A.N. Leontiev seja importante para demonstrar o destaque que tem na concepção histórico-cultural o conceito de perejivanie, e ainda que sua mais correta tradução para o português seja a palavra vivência, pois o modo como o ambiente e as especificidades da criança influenciam-na está definido na perejivanie, cabe uma crítica a sua posição. No trabalho denominado A crise dos sete anos (Krizis semi liet), Vigotski (2004a) discute o termo perejivanie. Cabe lembrar que esse termo está fortemente ligado também a outro conceito queé situação social de desenvolvimento. Vigotski diz que é muito diferente a percepção das vivências de um bebê e de uma criança de sete anos, pois existe uma enorme diferença entre sentir fome e saber que se está com fome. O bebê não sabe de suas próprias vivências, ou seja, não tem consciência delas. O que muda numa criança de sete anos é que surge a estrutura de vivências quando a criança começa a entender o que significa "estou feliz", "estou triste", "estou zangada", ou seja, surge uma orientação consciente em suas próprias vivências. Assim como a criança de três anos descobre suas relações com as pessoas, da mesma forma uma criança de sete anos descobre o próprio fato de suas vivências (Vigotski, 2004a).

Nesse trabalho, Vigotski chama a atenção para a importância de estudar a personalidade e o ambiente da criança como uma unidade. Porém, diz ele, na realidade, as tentativas de estudar em unidade as especificidades da criança e do ambiente social de desenvolvimento separam-nos previamente para, posteriormente, uni-los. Essa ideia de unidade perpassa toda a obra de Vigotski e está intimamente relacionada a seu método de análise. A mesma análise que ele apresenta para dizer que o pensamento e a fala formam uma unidade é utilizada por ele para dizer que a situação social de desenvolvimento e as especificidades da criança formam uma unidade. Perejivanie é definido por Vigotski (2004a) da seguinte forma:

Perejivanie para a criança é exatamente uma unidade simples, relativa à qual não se pode dizer que represente uma influência do ambiente sobre a criança ou uma especificidade da criança; perejivanie é exatamente a unidade da personalidade e do ambiente, assim como está representada no desenvolvimento. Por isso, no desenvolvimento, a unidade dos aspectos da personalidade realiza-se numa série de perejivanie da criança. Perejivanie deve ser entendida como uma relação interna da criança como pessoa com um ou outro aspecto da realidade (p.188).

No entanto, a visão de Leontiev é paralelista, interacionista, pois, para ele, o ambiente social e as peculiaridades da criança existem de forma independente um do outro, muito embora interajam. Já para Vigotski, por sua vez, a situação social e as especificidades da criança formam uma unidade. Perejivanie, para ele, não diz respeito a uma particularidade da criança, nem ao ambiente social em que ela se encontra, mas à relação entre os dois. O ambiente tem sentidos diferentes para crianças em fases de vida diferentes. Do ponto de vista psicológico, numa determinada situação social de desenvolvimento, duas crianças - uma de cinco meses e outra de cinco anos - embora estejam no mesmo espaço, não vivenciam de modo equivalente o ambiente, porque as suas especificidades estão em jogo; a criança de cinco meses percebe a situação de uma forma e a de cinco anos de outra; portanto, cada uma tem a sua vivência, e o ambiente social não é equivalente para ambas. Ou seja, o ambiente não existe em absoluto; para compreender e estudar o desenvolvimento humano, é preciso conhecer o ambiente na sua relação com as especificidades de cada indivíduo. Não existe ambiente social sem o indivíduo que o perceba e o interprete. O ambiente social é uma realidade que envolve o ambiente e a pessoa, é o entre.

Por essa razão, vê-se a importância de discutir a tradução para o português do conceito perejivanie. É um conceito que está presente em várias obras e tem um significado profundo para toda a teoria de Vigotski.

Nas traduções das obras de Vigotski para o inglês, o conceito perejivanie aparece como experiência (Minick, 1997, p.32). Mas, no artigo Periods in child development, de Mahn (2007), em que se discute o conceito de Vigotski, o autor diz que não existe, em inglês, um termo adequado para a tradução de perejivanie e que a tradução com uma ou duas palavras não faz justiça ao conceito. A crítica àquela opção dos tradutores ganha força quando se sabe que a língua russa tem a palavra opit para 
referir-se à experiência, aliás muito usada por Vigotski (2009) no livro Imaginação e criação na infância. Além disso, a palavra experiência não dá conta do significado atribuído por Vigotski a esse importante conceito em sua teoria, como exposto. Então, a palavra em português que com mais verossimilhança transmite o conceito perejivanie de Vigotski é vivência.

A palavra vivência, segundo o Dicionário Houaiss (2001), tem vários significados. Entre eles está a seguinte definição: "coisa que se experimentou vivendo, vivenciando; conhecimento adquirido no processo de viver ou vivenciar uma situação ou de realizar alguma coisa; experiência, prática". No mesmo dicionário, encontra-se a definição da palavra vivenciar como "viver (uma dada situação) deixando-se afetar profundamente por ela" (Houaiss, 2001, p.2.875). É nesse último sentido que Vigotski emprega a palavra perejivanie.

Como visto, é no livro Psicologia da arte, escrito em 1925, que aparece pela primeira vez o termo perejivanie de Vigotski. As duas outras obras citadas (Aulas de pedologia, 2001b e A crise dos sete anos, 2004a) pertencem à fase final da vida de Vigotski, 1929 e 1933, respectivamente. E é em $A$ crise dos sete anos que ele desenvolve mais detalhadamente o conceito e o significado que atribui a ele, em função de sua maior preocupação relacionada aos problemas do desenvolvimento infantil. Pode-se afirmar que várias traduções desconsideram esse fato e provocam interpretações equivocadas do pensamento de Vigotski, levando, por vezes, a atribuir à sua teoria o caráter de interacionista, assim desconsiderando sua firme posição monista.

\section{Psicologia pedagógica (Pedagoguitcheskaia psirrologuia)}

Esse importante livro - Psicologia pedagógica - foi entregue por Vigotski para publicação logo após sua apresentação no Congresso, em Petrogrado, em 1924.

꼰 Segundo larochevski (2007), a primeira versão foi pre眾 parada ainda em Gomel. Prova disso é o campo do $\underset{\infty}{\infty}$ formulário preenchido por Vigotski, ao ingressar no ? 1 Narcompros, no qual relaciona o livro como obra publi怘 cada: "Breve curso de psicologia pedagógica. Encontra-se na GIZ (Gossudarstvennoie Izdatelstvo - Editora Estatal)" (p.50). A publicação veio à luz em 1926. Durante

334 décadas, o livro não foi reeditado, ressurgindo nas prate- leiras das livrarias soviéticas apenas no final da década de 80. Segundo Vigodskaia e Lifanova (1996), nesse livro Vigotski (2005a) empreendeu a tentativa de apresentar uma análise da situação da psicologia mundial da época e das ciências relacionadas a ela. O livro, ainda segundo elas, é uma clara demonstração de como o autor queria pôr a psicologia a serviço da prática educacional na construção da nova sociedade socialista.

O presente livro tem o aspecto prático como objetivo principal. Ele gostaria de ajudar a nossa escola e o professor, contribuindo para a elaboração da compreensão científica do processo pedagógico em função dos novos dados da ciência psicológica (p.3).

Em Psicologia pedagógica já pode ser observada a abordagem dialética sobre o desenvolvimento humano; é nesse livro que Vigotski dá início a reflexões sobre o papel do ambiente social, bem como sobre a relação entre instrução e desenvolvimento.

Dividido em 19 capítulos, o livro apresenta ideias e conceitos fundamentais da pedagogia e da psicologia. Logo no início, o autor faz a diferenciação entre ambas, para chegar ao que se denomina psicologia pedagógica. Para ele, a pedagogia está no limiar entre a filosofia e a biologia. Ele recorre a Blonski, para quem a pedagogia filosófica gera a utopia pedagógica. Porém, a pedagogia científica inicia seu trabalho não com o estabelecimento de ideais, normas ou leis, mas com base no estudo do desenvolvimento de fato do organismo que está sendo educado e da ação mútua de fato entre este e o meio educacional (Vigotski, 2005a). Vigotski acrescenta que a pedagogia, por ser uma ciência específica e empírica, apoia-se em outras auxiliares, tais como a ética social, a psicologia e a fisiologia.

Em seguida, ao tratar da psicologia, o autor faz comentários breves a respeito de seu surgimento: inicialmente como uma ciência sobre o espírito, tendo sido por isso denominada psicologia metafísica; posteriormente, sobre quando ocorreu a diferenciação entre a psicologia metafísica e a positivista; depois, como a psicologia começou a ser denominada por Lange como "psicologia sem espírito" (Vigotski, 2005a, p.9) e se transformou na psicologia empírica ou na psicologia sem qualquer metafísica ou na psicologia baseada na experiência. No entanto, para Vigotski (2005a), apesar de a psicologia deixar de lado uma boa dose da metafísica, ela não se igualou às ciências naturais e passou a ser 
compreendida como uma ciência sobre os fenômenos espirituais da consciência. Isso, para o autor, fez com que a psicologia se fechasse numa consciência sem a existência, estando condenada à morte, ao isolamento da realidade e à fragilidade diante das questões essenciais sobre o comportamento humano (Vigotski, 2005a).

Vigotski (2005a) chega à psicologia do comportamento e critica a tendência norte-americana que a interpreta como um processo de interação entre o organismo e o meio, em que o princípio explicativo torna-se o princípio da utilidade biológica da psique. Para ele, a psicologia estuda o comportamento social do ser humano e as leis de mudança desse comportamento; assim, a nova psicologia deve ser materialista, objetiva, dialética e biossocial. Para concluir, chama atenção para a crise que a psicologia vivia à época, afirmando que isso não significava que ela devesse se apoiar apenas em material novo, e, sim, utilizar aquilo que era cientificamente importante da velha psicologia.

Começando a tratar da psicologia pedagógica, Vigotski (2005a) diz que, no século XIX, o experimento provocou uma ruptura na psicologia. Esta passou a pleitear seu lugar entre as ciências exatas e, do desejo de ser uma ciência aplicada, surgiu a psicologia pedagógica, sob cuja orientação o processo educacional aparentemente se tornaria tão preciso quanto a técnica. O autor ressalta, porém, que a psicologia pedagógica deve ser vista como uma ciência independente, como um ramo da psicologia aplicada e que seria um erro identificá-la com a pedagogia experimental:

O mais correto seria diferenciar: 1) a pedagogia experimental que soluciona questões puramente pedagógicas e didáticas por meio dos experimentos (escola experimental); 2) a psicotécnica pedagógica, análoga aos outros campos da psicotécnica e que se ocupa das investigações psicológicas aplicadas à educação (Vigotski, 2005a, p.18).

No Brasil, Psicologia pedagógica saiu em duas edições. Em 2001, foi publicada a primeira edição, pela Martins Fontes, com tradução do russo realizada por Paulo Bezerra (Vigotski, 2004b). Na ficha técnica do livro não há informação sobre a edição a partir da qual foi realizada a tradução para o português, somente o título em russo. Mas tudo leva a crer que foi de uma edição mais recente. $O$ que chama a atenção é que essa edição brasileira da Martins Fontes acrescenta ao livro dois capítulos que não existem no original: o XX (O problema do ensino e do desenvolvimento mental na idade escolar) e o XXI (A dinâmica do desenvolvimento mental do aluno escolar em função da aprendizagem), além de outros dois textos apresentados como avulsos (Desenvolvimento dos conceitos cotidianos e científicos na idade escolar Análise pedológica do processo pedagógico). É relevante ressaltar a descaracterização desse livro na edição da Martins Fontes. Os dois textos que estão relacionados como capítulos XX e XXI não fazem realmente parte do livro Psicologia pedagógica. O primeiro, O problema da instrução e do desenvolvimento mental na idade escolar (Problema obutchenia iumstvennogo razvitia v chkolnom vozraste), foi um artigo escrito entre 1933/1934, e o segundo, Dinâmica do desenvolvimento mental do escolar em função da intrução (Dinamika umstvennogo razvitia chkolnika v sviazi s obutcheniem), foi uma palestra proferida por Vigotski na cátedra de defectologia do Instituto de Pedagogia Bubnov, em 23 de dezembro de 1933.

Existem publicações russas que acrescentaram alguns outros textos em suas edições, mas não como capítulos integrantes do trabalho de Psicologia pedagógica. Por exemplo, o livro da editora AST, Astrel Liuks, de 2005, que tem como título Pedagoguitcheskaia psirrologuia (Psicologia pedagógica) está dividido em três partes. A primeira compreende os 19 capítulos de Psicologia pedagógica; a segunda reúne quatro textos do autor sob o título O desenvolvimento mental das crianças no processo de instrução (Umstvennoie razvitie detei $v$ protsesse obutchenia) e a terceira parte traz o importante trabalho de Vigotski O instrumento e o signo no desenvolvimento da criança (Orudie i znak v razvitii rebionka). Para quem estuda Vigotski essa informação é importante, já que a edição brasileira da Martins Fontes induz o leitor a pensar que o livro Psicologia pedagógica foi escrito do modo como apresentado, uma vez que não foi feito nenhum comentário a respeito dos acréscimos. Não se pode deixar de revelar também o detalhe de que o texto avulso A análise pedológica do processo pedagógico, que também faz parte da edição da Martins Fontes, não foi publicado na íntegra. O original, que é uma palestra de Vigotski proferida em 17 de março de 1933 no Instituto Experimental de Defectologia Epstein, tem 26 páginas e não seis, conforme a referida edição. Pode-se supor que a edição russa da qual foi traduzido apresente o texto cortado; no entanto, como a editora 
não faz nenhuma menção à edição a partir da qual foi realizada a tradução, torna-se impossível a investigação do problema que justificaria o ocorrido.

E, finalmente, pode-se afirmar que a edição russa que Bezerra traduziu para o português foi aquela que sofreu alterações. Um bom exemplo disso é que, no texto original de 1926, no final do capítulo XIX, há uma citação do livro Literatura erevolução de Lev Davidovitch Trotski. Já na edição da Martins Fontes o nome de Trotski sequer aparece, e o longo trecho citado de sua obra está integrado ao texto como se fosse do próprio Vigotski. Essa falha não se verifica na edição de Psicologia pedagógica publicada pela Artmed a partir da edição argentina, organizada por Guillermo Blanck, com tradução do espanhol para o português feita por Claudia Schilling: o nome de Trotski não foi omitido e a longa citação de um de seus textos está entre aspas. Além disso, na nota n¹1 referente ao capítulo XIX, Blanck comenta que, nas edições estadunidenses, a citação de Trotski também foi omitida (Blanck, 2003b).

Uma questão interessante que é abordada no prefácio de Blanck (2003b) é a atribuição a A.N. Leontiev de responsabilidade pelo rebatizado da teoria histórico-cultural por histórico-social no obituário de L.S. Vigotski, publicado no volume $n^{\circ} 6$ da revista Sovetskaia psirronevrologuia de 1934. Em seu texto, Leontiev (1983) realmente se refere à teoria psicológica criada por Vigotski como obchestvenno-istoritcheskaia (sócio-histórica):

A interpretação de L.S. Vigotski da estrutura mediada dos processos psicológicos e do psiquismo como atividade humana serviu de pedra angular, de base para toda a teoria psicológica científica elaborada por ele - a teoria sócio-histórica (o "cultural" em contraposição ao "natural") do desenvolvimento da psique do homem. Com isso foi criada a necessidade de ruptura, numa investigação concreta, do círculo vicioso das ideias psicológicas naturalistas abordadas

- O referido decreto proibiu a pedologia e a atuação dos pedólogos na União Soviética. L.S.Vigotski elaborou estudos sobre a pedologia e, mesmo tendo apresentado críticas ao trabalho dos pedólogos nas escolas soviéticas, seus trabalhos foram considerados nocivos. A tradução do decreto encontra-se na 336 e publicada em 1983, o referido obituário só havia sido publicado uma vez, logo após a morte de Vigotski. Sabe-se que este, segundo larochevski (2007), não deu nome algum a sua teoria, assim como também é sabido que a ela, atualmente, são atribuídos diferentes nomes: sócio-histórica, sociocultural, sociointeracionista, entre outros. Outro detalhe importante é que, em diferentes trabalhos de A.N. Leontiev escritos em anos posteriores, ele se refere à teoria de Vigotski como histórico-cultural: por exemplo, em Sobre a abordagem histórica no estudo da psique humana (Ob istoritcheskom podrrode v izutchenii psirriki tcheloveka), de 1959 (Leontiev, 1983), e no final do Vigotski, de 1982 (Leontiev, 1982). Esses fatos levam à formulação das seguintes perguntas: quando foi exatamente que a teoria de Vigotski passou a ser denominada de histórico-cultural e por que, mesmo na época do "degelo" dos anos pós-stalinistas e mais tarde, enquanto estava vivo, A.N. Leontiev não publicou mais o texto em que se referiu à teoria de Vigotski como sócio-histórica? Por que, no mundo ocidental, o termo sócio-histórico ou sociointeracionista é usado com muita frequência para se referir à teoria de Vigotski?

\section{Pensamento e fala (Michlenie i retch)}

Michlenie i retch (Pensamento e fala) foi o último livro de Vigotski, que, enquanto sistematizava e organizava os últimos capítulos desse valioso trabalho, vivia seus últimos dias. Devido a seu frágil estado de saúde, alguns capítulos foram ditados a uma estenógrafa e, depois de datilografados, corrigidos pelo autor (Blanck, 2003a).

Diferentemente de Psicologia da arte, Michleniei retch foi publicado no final de 1934, seis meses após a morte de seu autor. Essa foi a primeira edição russa, com 323 páginas, publicada pela editora Sotsekgiz (Vigodskaia \& Lifanova, 1996, p.407). No entanto, com o decreto de 4 de julho de 1936', dois anos depois, o livro, sem obter qualquer crítica por parte dos estudiosos, entrou para o rol de obras proibidas (Vigodskaia \& Lifanova, 1996). prefácio que fez ao volume 1 das Obras reunidas de coletânea que contém as obras de A.N. Leontiev, editada passo em direção à nova psicologia (p.19).

Segundo o comentário dos organizadores da íntegra em (Prestes, 2010). 
Um momento muito importante para a psicologia soviética foi a publicação, em 1956, de sua segunda edição, que saiu em Estudos psicológicos selecionados (Izbrannie psirrologuitcheskie issledovania) - uma coletânea de trabalhos de Vigotski que, além de Michlenie i retch, incluiu também outros trabalhos importantes. A terceira edição soviética foi publicada no volume 2 das Obras reunidas, no início dos anos 1980. Posteriormente, o livro teve várias edições.

Excetuadas a primeira edição, de 1934, e algumas mais recentes, como a da editora Labirint, de 2001, pode se afirmar que Michlenie e retch foi o livro de Vigotski que mais sofreu adulterações e cortes. Guita narra em seu livro como conseguiu, junto a A.R. Luria, que não fosse retirado na edição de 1956 o capítulo 2 - As raízes genéticas do pensamento - e como este, após intensas conversações com o censor, parabenizou-a por ter defendido o trabalho do pai, dizendo a ela: "Sairá na íntegra" (Vigodskaia \& Lifanova, 1996, p.349). No entanto, não foi o que ocorreu, como será visto adiante.

O quadro abaixo foi elaborado com o intuito de facilitar a leitura de informações a respeito das diferentes edições russas e soviéticas de Michlenie i retch sobre as quais alguns dados foram obtidos ou às quais foi possível ter acesso (Quadro 2).

Para o presente trabalho, a comparação do texto de Michlenie i retch envolveu as seguintes edições russas e soviéticas: Vigotski, L.S. Sobranie sotchineni. Moskva: Pedagoguika, 1982,Tom 2, pp. 5-361 (com 356 páginas); Vigotski, L.S. Michlenie iretch. Moskva: Labirint, 2001 (com
366 páginas); Vigotski, L.S. Psirrologuia. Moskva: Aprel Press, Eksmo-Press, 2002 , p. 262-509 (com 247 páginas) (Vigotski, 2002b). Embora Guita Lvovna diga em seu livro que a coletânea de 1956 saiu graças a A. R. Luria, a organização da publicação ficou a cargo dela, de A. N. Leontiev e A. R. Luria, conforme comentário 1 do volume 2 das Obras reunidas em russo (Vigotski, 1982, p.481). Apesar de dizer também que não houve cortes, não foi o que aconteceu, pois a edição de Michlenie i retch, que está no volume 2 das Obras reunidas de 1982, foi publicada assim como está na coletânea de 1956 e contém cortes e paragrafação diferente do original de 1934.

Somente em 2001, pela editora Labirint, saiu, na Rússia, a segunda edição integral de Michlenie i retch, sem cortes e sem alterações. Apesar de não mencionar que a publicação foi feita com base na edição de 1934, essa versão do livro apresenta ao final um trecho do comentário de Kolbanovski (2001), editor da primeira edição, a respeito do texto de Michlenie i retch e lista as correções que ele fizera:

... com o objetivo de conservar intocável o trabalho póstumo do autor, limitei-me a introduzir as correções estritamente necessárias. Desse modo, a última obra de L.S.Vigotski está sendo publicada assim como me foi entregue para editoração (p.362).

Em seguida, um comentário feito pelos editores confirma que as edições de 1956 e de 1982 não mantiveram o estilo da fala do autor e que até mesmo na versão que está no volume 2 das Obras reunidas (Vigotski, 1982) percebem-se grandes omissões, além de correções

Quadro 2. A trajetória editorial de Michlenie i retch (Pensamento e fala), de L.S. Vigotski.

\begin{tabular}{|c|c|}
\hline Edição de 1934: Vigotski (1934) & $\begin{array}{l}\text { Texto publicado na íntegra, com correções estritamente necessárias, segundo o editor, V. Kolbanovski. } \\
\text { Não houve cortes nem correções ao estilo do autor, preservando-se suas frases longas e reiterações } \\
\text { textuais }\end{array}$ \\
\hline Edição de 1956: Vigotski (1956) & $\begin{array}{l}\text { Após ficar } 22 \text { anos censurado, o livro sai numa coletânea de obras intitulada Izbrannie } \\
\text { psirrologuitcheskie issledovania, organizada por G. L. Vigodskaia, A. N. Leontiev e A. R. Luria. O texto } \\
\text { de Michlenie i retch publicado nessa coletânea sofre cortes de parágrafos inteiros e correções. } \\
\text { Portanto, não é o mesmo texto que saíra em } 1934\end{array}$ \\
\hline Edição de 1982: Vigotski (1982) & $\begin{array}{l}\text { Após um longo interstício, o texto de Michlenie i retch é publicado no volume } 2 \text { das Obras reunidas } \\
\text { em } 6 \text { volumes. O texto repete a publicação de 1956, portanto, não está na íntegra }\end{array}$ \\
\hline Edição de 2001: Vigotski (2001b) & $\begin{array}{l}\text { Segundo comentário apresentado no livro, o texto é integral, tal como saiu em 1934. Na comparação } \\
\text { feita com as versões adulteradas, ou seja, com as supressões, foi possível identificar os trechos que } \\
\text { foram omitidos naquelas versões }\end{array}$ \\
\hline Edição de 2002: Vigotski (2002a) & $\begin{array}{l}\text { A coletânea repete a edição de Michlenie i retch com cortes, ou seja, de } 1956 \text { e 1982. A paragrafação, } \\
\text { que deveria ser igual à dessas edições, está diferente }\end{array}$ \\
\hline
\end{tabular}


estilísticas. Por exemplo, desapareceram as repetições, mas com elas foi-se também o sentido daquilo que o autor queria dizer: "Por exemplo, em Vigotski está: 'O coeficiente raramente caía até zero', com a correção do redator o mesmo coeficiente'caía bruscamente atézero"' (Vigotski, 1982, p. 362). Algumas outras correções são destacadas, tais como: sempre que apareciam os termos "funções psicológicas"eles eram alterados para"funções psíquicas"; o capítulo 1, no original de Vigotski, tinha somente 2 grandes parágrafos o que, segundo os redatores, dificultava a leitura. Então, tomou-se a decisão de dividi-los em vários parágrafos; foram corrigidas algumas grafias de nomes - de Sepir para Sapir, de Gros para Groos; o nome de P.P. Blonski foi omitido no final do terceiro parágrafo do subcapítulo 18 do capítulo 5 .

Ao longo do trabalho de comparação de diferentes edições soviéticas e russas de Michlenie i retch, foram identificadas várias diferenças entre as edições às quais se teve acesso. Por exemplo:

- Existem trechos inteiros suprimidos, como o terceiro, quarto e quinto parágrafos do capítulo 2 - Problema retchi i michlenia rebionka $v$ utchenii Piaget $(\mathrm{O}$ problema da fala e do pensamento da criança nos estudos de Piaget);

- A paragrafação das edições de 1982 e 2002 é idêntica, mas difere da que está na edição de 2001. Então, mesmo a edição mais recente preserva as alterações feitas pelos editores da coletânea de 1956.

Pode-se indagar: Qual motivo levou os editores a alterarem o estilo e a paragrafação, e a cortarem trechos inteiros, em 1956? Por que as adulterações foram mantidas na edição de 1982?

Após sofrer adulterações em seu próprio país, Michlenie i retch veio ao mundo em sua primeira versão em inglês, em 1962 - Thought and language, editada pelo Instituto Tecnológico de Massachusetts, com 168 páginas. No mesmo ano, saiu uma edição japonesa. A edição em inglês veio à luz em forma resumida a critério dos editores e com a bênção de A.R. Luria. Guita Lvovna Vigodskaia (Vigodskaia \& Lifanova, 1996) relata em seu livro, transcrevendo trecho de uma carta de A.R. Luria enviada à tradutora:

Recebi o volume de Vigotski traduzido pela senhora. Seria necessário dizer a satisfação que provocou em mim? Uma tradução maravilhosa, uma seleção inteli338 gente do material, maravilhosa redação e um prefácio amistoso e condizente de Bruner. O ponto máximo é a surpresa: comentários de Piaget sobre a crítica de Vigotski. Que ideia inteligente de enviar para ele a tradução e receber anotações críticas. Não conheço na história da ciência nenhum caso em que dois destacados cientistas, e um deles ainda em vida, dividissem seus pontos de vista com uma diferença de 30 anos! Tenho a certeza de que o livro será um grande sucesso e provocará um amplo debate (p.138).

E foi essa versão, resumida, na qual sobraram apenas 168 páginas do original, que se multiplicou rapidamente no Ocidente e deu origem a traduções em vários países, incluindo o Brasil. Além da edição de 1962, o livro saiu em 1965, 1966, 1967, 1979, 1986, em inglês. Questionada sobre a edição americana, em entrevista à primeira autora deste estudo (Prestes, 2010), concedida em Moscou, em 2007, Guita Lvovna respondeu que o mais importante era a publicação. Além do mais, A. R. Luria tinha empreendido um esforço incomum para isso. Então, disse Guita, seria uma descortesia retribuir com reclamação a respeito de uma publicação que, durante décadas, permaneceu à margem da psicologia ocidental. No entanto, é preciso questionar o corte de aproximadamente $40 \%$ da obra. Certamente não deve ter sido apenas o estilo reiterativo do autor que levou a essa decisão.

Em português, o livro saiu pela primeira vez em 1979, publicado em Portugal pela editora Antídoto, a partir da edição em inglês. Outra edição portuguesa foi lançada em 2001 pela editora Estratégias Criativas, cuja ficha técnica indica que o texto publicado foi traduzido do original russo que está no volume 2 das Obras reunidas.

No Brasil, a primeira edição dessa obra de Vigotski apareceu em 1987 pela editora Martins Fontes, sob o título Pensamento e linguagem (Vigotski, 2005b). A tradução foi feita do inglês por Jefferson Luiz Camargo, a partir daedição do Instituto Tecnológico de Massachusetts. Desde então, essa versão não para de ser reeditada, encontrando-se atualmente em sua 3 a edição.

Em 2001, no Brasil, foi publicada pela mesma Martins Fontes a versão completa de Michlenie e retch sob o título A construção do pensamento e da linguagem, traduzida diretamente do russo por Paulo Bezerra 
(Vigotski, 2001c). Na ficha técnica do livro não está indicada a edição russa da qual foi traduzida para o português, mas, ao comparar com a edição russa integral de 2001, pode-se afirmar que é o texto completo, pois contém todos os trechos suprimidos na edição soviética retalhada de 1956. O inadmissível é uma mesma editora publicar duas versões da obra de Vigotski como se fossem livros diferentes. Na verdade, até o são, já que a edição resumida não pertence à pena do pensador e sim a seus editores, que a adulteraram, atribuindo a autoria a Vigotski.

Ao se analisar a palavra russa michlenie, traduzida nas edições brasileiras como pensamento, pode-se supor que o pensador soviético refere-se ao raciocínio e não ao pensamento, pois, no russo, existem duas palavras muito próximas (mis/ e michlenie) que podem significar ideia, raciocínio e pensamento. Por exemplo, o livro de Potiebnia (1993), que Vigotski leu e cita muito em seus trabalhos, intitula-se Misl i iazik e pode ser traduzido como Pensamento e língua ou Ideia e língua. As duas palavras possuem o mesmo radical [mis/], só que, no russo, quando a palavra termina em [ie] está indicando um processo, assim como ocorre com a palavra obutchenie (Mariz, 2009). Ao aprofundar os estudos sobre Michlenie i retch em russo, é possível concluir que a palavra michlenie refere-se aos processos da atividade do pensar. Logo, está corretamente traduzida como pensamento.

Em relação à palavra retch é preciso dizer que sua tradução para o português precisa de maiores cuidados. É claro que o livro de Vigotski ficou consagrado mundialmente com o título Thought and Language (Pensamento e linguagem), ou Pensée et langage, em francês; Pensiero elinguaggio, em italiano; Pensamiento y lenguaje, em espanhol e Denken und Sprechen, em alemão. Foi com esse título que se transformou em um clássico e em leitura obrigatória nos mais diversos cursos de graduação e pós-graduação - apesar de todos os problemas de corte e adulterações. No entanto, algumas traduções para o inglês corrigiram, de um tempo para cá, o título para Thinking and speech, revelando que no inglês a palavra speech (e não mais language) transmite com maior precisão a palavra russa retch.

Isso não ocorreu no Brasil, pois as traduções existentes aqui ainda adotam o título Pensamento e linguagem e utilizam muito mais os argumentos dos dicionários para justificar as escolhas feitas do que propriamente as questões abordadas por Vigotski em seus estudos. $\bigcirc$ que mais espanta é que certa editora, numa evidente jogada de marketing, publicou o livro de A.R. Luria, intitulado em russo Soznanie eiazik (Consciência elíngua) sob o título Pensamento e linguagem: as últimas conferências de Luria (Nesse livro, estão as últimas palestras proferidas por Luria e nelas está destacada a importância da língua para o surgimento e o desenvolvimento da consciência humana) (Luria, 1987). A irresponsabilidade dessa publicação é tamanha que, além de não dizer se foi traduzida do russo - pois indica somente que a "obra foi originalmente publicada em russo sob o título lazik \& Sosnanie" - confunde, ao longo da tradução do texto do livro, linguagem e língua, linguagem e fala. Além do que, a palavra soznanie não quer dizer pensamento e sim consciência.

É importante destacar também que recentemente, em 2007, pesquisadores argentinos realizaram uma tradução de Michlenie iretch, publicada com o título Pensamento e habla, pela editora Colihue Clásica. Mais uma vez, os estudiosos argentinos realizaram um trabalho competente de resgate da obra original do pensador soviético, assim como, em sua época, o fez Guillermo Blanck com Psicologia pedagógica. Além de traduzir para o espanhol a partir do original russo de 1934 (ao contrário do que fez a primeira edição em inglês que apresenta como folha de rosto uma cópia da capa da edição soviética de 1934, para induzir o leitor a não ter dúvidas da procedência da obra!), a edição da Colihue Clásica apresenta uma introdução histórica riquíssima, de Marcelo Caruso; uma introdução teórica, de Félix Temporetti; e notas do tradutor, de Alejandro Ariel González. Cabe ainda ressaltar que o tradutor, com muita responsabilidade e conhecimento, explicita suas escolhas, mostrando que seu papel não se restringiu a meramente verter de uma língua para a outra. O nome do tradutor está em lugar de destaque na página de rosto da edição e ele demonstra profundos conhecimentos da vida e obra do autor. Essa edição argentina merece reconhecimento pela seriedade com que tratou esse importante trabalho de Vigotski e inaugura oficialmente uma mudança radical ao traduzir retch não como linguagem e sim como fala.

\section{Referências}

Blanck, G. (2003a). Notas. In L. S. Vigotski. Psicologia pedagógica (pp.305-306). Porto Alegre: Artmed. 
Blanck, G. (2003b). Prefácio. In L. S. Vigotski. Psicologia pedagógica (pp.15-32). Porto Alegre: Artmed.

Elkonin, D. B. (1984). Prefácio. In L. S. Vigotski. Sobranie sotchineni v chesti tomarh (Tomo 4, pp.386-403). Moskva: Pedagoguika.

Houaiss, A. (2001). Dicionário Houaiss da língua portuguesa. Rio de Janeiro: Objetiva.

larochevski, M. G. (2007). L. S. Vigotski: v poiskarh novoi psirrologii. URSS: Moskva.

Ivanov, V. V. (1986). Commentarii 75. In L. S. Vigotski. Psirrologuia iskusstva (pp.193). Moskva: Iskusstvo.

Kolbanovski, V. (2001). Tekstologuitcheski comentari (pp.362). In L. S.Vigotski. Michleniel retch. Moskva: Labirint.

Leontiev, A. A. (1983). Borba za problemu soznania v stanovlenii sovetskoi psirrologii. In A. N. Leontiev. Izbrannie psirrologitcheskie proizvedenia. Moskva: Pedagoguika.

Leontiev, A. A. (Org). (2007). Slovar L. S. Vigotskogo. Moskva: Smisl.

Leontiev, A. N. (1982). Vstupitelnaia statia. In L. S. Vigotski. Sobranie sotchineniiv chestitomarh. Moskva: Pedagoguika.

Leontiev, A. N. (1983). Izbrannie psirrologuitcheskie proizvedenia (pp.96-141). Moskva: Pedagoguika.

Leontiev, A. N. (1986). Vstupitelnaia statia. In L. S. Vigotski. Psirrologuia iskusstva (pp.1-6). Moskva: Iskusstvo.

Leontiev, A. N. (2003). Stanovlenie psirrologuii deiatelnosti. Moskva: Smisl.

Luria, A. R. (1987). Pensamento e linguagem: as últimas conferências de Luria. Porto Alegre: Artes Médicas.

Mahn, H. (2007). Periods in child development. In A. Kozulin, B. Gindis, V. S. Ageyev \& S. M. Miller. Vygotsky's educational theory in cultural context. New York: Cambridge University Press

Mariz, T. G. (7 de julho de 2009). Comunicação pessoal. Manuscrito não-publicado. Rio de Janeiro: UFRJ.

Minick, N. (1997). The development of Vygotsky's thought: an introduction. In L. S. Vygotsky. The collected works of L. S. Vygotsky (Vol. 1). New York: Plenum Press.

Potiebnia, A. A. (1993). Mis/ i iazik. Kiev: Sinto.

Prestes, Z. R. (2010). Quando não é quase a mesma coisa: análise de traduções de L.S. Vigotski no Brasil, repercussões no campo educacional. Tese de doutorado não-publicada, Faculdade de Educação, Universidade de Brasília.
Trotski, L. D. (2007). Literatura e revolução. Rio de Janeiro: Jorge Zahar.

Tunes, E. (2000). Os conceitos científicos e o desenvolvimento do pensamento verbal. Cadernos Cedes, 35, 36-49.

Vigodskaia, G. L., \& Lifanova, T. M. (1996). Lev Semionovitch Vigotski:jizn, deiatelnost, chtrirri k portretu. Moskva: Smisl i Smisl.

Vigotski, L. S. (1934). Michlenie i retch. Leningrad: Sotsekguiz. Vigotski, L. S. (1956). Michlenie i retch. Moskva: Izdatelstvo. Vigotski, L. S. (1982). Michlenie i retch. Moskva: Pedagoguika. Vigotski, L. S. (1986). Psirrologuia iskusstva. Moskva: Iskusstvo.

Vigotski, L. S. (1998). Psirrologuiaiskusstva. Minsk: Sovremennoie slovo.

Vigotski, L. S. (2001a). Psicologia da arte. São Paulo: Martins Fontes.

Vigotski, L. S. (2001 b). Michlenie e retch. Moskva: Labirint.

Vigotski, L. S. (2001c). A construção do pensamento e da linguagem. São Paulo: Martins Fontes.

Vigotski, L. S. (2002a). Michlenie i retch. In Psirrologuia. Moskva: Aprel Press.

Vigotski, L. S. (2002b). Psirrologia. Moskva: Eksmo.

Vigotski, L. S. (2003). Psicologia pedagógica. Porto Alegre: Artmed.

Vigotski, L. S. (2004a). Psirrologuia razvitia rebionka. Moskva: Eksmo.

Vigotski, L. S. (2004b). Psicologia pedagógica. São Paulo: Martins Fontes.

Vigotski, L. S. (2005a). Pedagoguitcheskaia psirrologuia. Moskva: AST.

Vigotski, L. S. (2005b). Pensamento e linguagem. São Paulo: Martins Fontes.

Vigotski, L. S. (2009). Imaginação e criação na infância. São Paulo: Editora Ática.

Zaverchneva, E. I. (2007). Plan polnogo sobrania sotchineni L. S. Vigotskogo. Non-published manuscript. Moskva.

Recebido em: 6/5/2010

Aprovado em: 25/8/2011 